\title{
Polímeros para a indústria têxtil
}

\section{Introdução}

Todas as fibras, quer sejam naturais ou artificiais, são constituídas por uma estrutura molecular representada por uma cadeia linear mais ou menos comprida e disposta sensivelmente segundo o seu eixo. É esta disposição que lhe confere as suas características particulares, nomeadamente a tenacidade, pois permite às moleculas suportarem axialmente os esforços de traç̧ão a que as fibras são submetidas. Durante a fabricação das fibras artificiais, pela estiragem a que são submetidas, as moléculas reajustam o seu posicionamento, paralelizando-se, endireitando-se e aproximando-se umas das outras, ao mesmo tempo que melhoram a sua orientação axial. De certo modo, podemos dizer que se passa a nível molecular, um fenómeno semelhante ao que acontece durante o fabrico dum fio constituído por fibras têxteis, por acção das estiragens aplicadas pelas diferentes máquinas. Esta maior orientação molecular corresponde a uma aumento do grau de cristalinidade da fibra, como se pode observar pelas imagens de difracção com Raios X, ou pelo aumento do índice de refracção transversal (birrefringência).

Para um polimero poder ser transformado em fibras é necessário primeiramente que as suas moléculas sejam separadas e desembaraçadas umas das outras o que se consegue quer por dissolução, mediante um solvente apropriado, que mais tarde será eliminado, quer por amolecimento e fusão conseguidos pela aplicação de calor. A substância viscosa obtida por qualquer dos métodos é seguidamente passada por meio de pressão através dos orifícios das fieiras e seguidamente solidificada ou coagulada em forma de filamentos, o que se consegue por arrefecimento no caso das substâncias fundidas, por eliminação do solvente ou por neutralização do banho. Pelo primeiro processo apontam-se como exemplos os fabricos de algumas fibras acrílicas, enquanto que o fabrico das fibras de celulose regenerada (viscose) se baseia na coagulação dos filamentos por neutralização do solvente (soda cáustica) por meio de ácido sulfúrico.

Existem outros processos mais sofisticados capazes de produzir fibras a partir de massas viscosas, mas em regra o seu interesse é apenas laboratorial (caso do crescimento de cristais lineares).

À saída da fieira os filamentos ainda não completamente solidificados ou coagulados, são puxados com uma velocidade constante o que vem favorecer a reorientação das moléculas que têm tendência a ficar mais direitas e paralelas ao eixo das fibras. Mais tarde essa orientação molecular poderá ainda ser melhorada por novas estiragens dos filamentos a temperaturas inferiores aos seus pontos de amolecimento.

\section{Propriedades dos polímeros têxteis}

Para uma matéria plástica poder ser transformada em filamentos, é fundamental que a sua estrutura química tenha a seguinte constituição:

1. Ser constituída por polimeros lineares, sem ligaçð̃es laterais entre si.

2. Ter um comprimento molecular adequado.

Além destas características fundamentais, e para efeitos práticos de aplicação, é conveniente que as matérias plásticas destinadas ao fabrico de fibras obedeçam igualmente às seguintes condiçð̋es:

3. Poderem ser facilmente transformadas numa massa viscosa.

4. Terem um ponto de fusão ou amolecimento suficientemente elevado.

5. Serem resistentes aos agentes químicos comuns, nomeadamente ao oxigénio do ar e à luz solar.

6. Serem incolores, inodoros, não tóxicos nem alergénicos.

7. Serem de possível tingimento pelos meios ao dispor da indústria têxtil.

8. Poderem ser produzidas a partir de matérias-primas de preço acessível.

\section{Linearidade molecular}

Todas as fibras artificiais, a exemplo das fibras naturais, são constituídas por polímeros lineares sem ligações laterais. A lã constitui uma excepção pois as suas cadeias moleculares de aminoácidos estão ligadas entre si por átomos de enxofre (-S-S-). A fibra de lã só poderia ser dissolvida se previamente essas ligaçð̃es de cistina fossem quebradas. Com efeito, a formação de fibras exige uma movimentação das moléculas, só possível se não existirem ligações intermoleculares que tal impeçam. Excluídas as moléculas produtoras de estruturas tridimensionais, a linearidade das moléculas é um elemento fundamental. Com efeito, e não havendo ligaçð̃es químicas intermoleculares, a estabilidade da fibra só pode ser conseguida se as moléculas lineares se puderem aproximar de tal modo que as forças de Van der Walls e covalências se possam exercer com valores significativos. Isso por outro lado pressupøe duas coisas: que não existam cadeias laterais excessivamente volumosas e que o polímero tenha uma elevada capacidade de se orientar segundo o eixo da fibra, ou por outras palavras, de aumentar o índice de cristalinidade. Para que isso se verifique, importa que as moléculas criadoras dos polímeros tenham os seus grupos reactivos dispostos em oposição. R. Hill e E. Walker dão,

\footnotetext{
ainicisa-Fibras Sintéticas, SARL - Portalegre.
} 
como exemplo, o que sucede com diferentes combinaçð̃es de poliester a partir do etilenoglicol e diferentes ácidos dicarboxílicos:

Cristalinidade dos Poliesteres de Etileno Glicol com Ácidos Aromáticos Dicarboxilicos

\begin{tabular}{|c|c|c|c|}
\hline Estrutura do ácido & $\begin{array}{c}\text { Cristali- } \\
\text { nidade }\end{array}$ & P.F. ${ }^{\circ} \mathrm{C}$ & $\begin{array}{c}\text { Capacidade } \mathrm{p} / \\
\text { a formação } \\
\text { de fibra }\end{array}$ \\
\hline nula & 108 & 63 & nula \\
\hline
\end{tabular}

De notar que o aumento da cristalinidade, vem acompanhado por um aumento do ponto de fusão, como resultado dum melhor "empacotamento" molecular só possivel com moléculas lineares. Na prática, as fibras são constituídas por zonas alternantes com diferentes graus de cristalinidade, pois nunca se consegue um paralelismo absoluto das moléculas lineares. Ao aplicarmos um esforço de tracção a uma fibra ela acabará por romper, por separação ou escorregamento, no seu ponto mais fraco, ou seja numa zona amorfa. Com efeito a ruptura das cadeias moleculares exigiria um esforço consideravelmente maior. Teoricamente, uma fibra totalmente cristalina deveria atingir uma tenacidade $5 \mathrm{a} 6$ vezes superior às que se conseguem na prática. Recentes progressos com fibras polietilénicas e polipropilénicas vêm demonstrar a razão do exposto. Com efeito, foi possível, mediante o emprego de novas técnicas de extrusão (gel spinning), obter fibras com grau extremamente elevado de orientação molecular. $\mathrm{O}$ resultado foram fibras com 5 a 6 vezes mais tenacidade que fibras de poliester de alta tenacidade correntemente utilizadas*. Para estes resultados, foi decisiva a possibilidade de obter fibras constituidas por moléculas de peso molecular muito elevado, graças ao novo sistema de extrusão que atrás mencionámos.

\section{Comprimento molecular}

Para o fabrico de fibras, as cadeias moleculares necessitam de ter um peso molecular adequado, caso contrário o comprimento das moléculas não é suficiente para durante uma estiragem serem arrastadas e ficarem paralelas e direitas. Pelo contrário, se o seu comprimento for muito exagerado existe grande dificuldade nessa estiragem pois o emaranhamento seria excessivo e o escorregamento intermolecular difícil. Em contrapartida, a um peso molecular elevado correspondem fibras mais resistentes. Segundo R. Hill (2) a capacidade para formar fibras, com o polietileno tereftalato, inicia-se com um P.M. de 13000 . Quanto ao nylon seria de 15000 e do Orlon 35500 . Como comparação assinale-se que as fibras polietilénicas de muito alta tenaci-

\footnotetext{
* A nova fibra polietilénica Spectra 1000, da Allied Corp. atinge 35 gp decitex contra os 6-7 usuais das fibras poliester de alta tenacidade. A firma holandesa DSM/Stanicarbon produz fibra semelhante a que dá o nome de Dyneema.
}

dade, obtidas pela nova técnica de "gel spinning" possuem um P.M. superior a 1000000 (3),

Staudinger demonstrou a relação existente entre o peso molecular e a viscosidade das soluçð̄es de polimero ou do polímero fundido. É essa medição que geralmente se utiliza na indústria para avaliar o grau de polimerização dos polímeros lineares, sendo essa viscosidade expressa em viscosidade intrínseca. Assim por exemplo, o polietileno tereftalato usado no fabrico de fibras tem em regra uma viscosidade intrínseca entre 0,70 (mais alta) e 0,48 (mais baixa). Para o fabrico de películas ou garrafas (PET) a viscosidade costuma ser maior, podendo atingir mais de 1,0 de viscosidade intrínseca.

\section{Outras condições}

A celulose foi o primeiro polimero a ser utilizado no fabrico de fibras. A grande dificuldade a resolver consistiu na descoberta dum processo de solubilização que permitisse a utilização da fieira e a sua transformação em filamentos. A sua transformação primeiro em derivado nitrado, (nitrato de celulose) e mais tarde em acetato (acetato e triaceto de celulose) permitiu tornear essa dificuldade uma vez que esses derivados da celulose são solúveis em solventes orgânicos comuns. Por evaporação do solvente obtinham-se os filamentos sólidos. Mais difícil foi encontrar um processo de dissolver a celulose sem alterar a sua composição química (viscose, celulose regenerada). Nesse caso, o xantato de celulose e a coagulação dos filamentos é obtida por neutralização da solução com ácido sulfúrico. No final obtêm-se filamentos constituídos por celulose cuja estrutura molecular é igual à original (obtida da polpa da madeira), salvo possuir um comprimento molecular inferior como resultado da degradação que as moléculas sofreram durante os tratamentos químicos.

A temperatura a que uma fibra tem de resistir sem perder propriedades, depende, como é evidente, das suas futuras aplicaçðes. Em princípio, admite-se que para a confecção de tecidos deve poder suportar a passagem a ferro o que significa um ponto de amolecimento de pelo menos $180-200^{\circ}$ C. Para outras aplicaçðes, como por exemplo fabrico de cordas, podem-se admitir temperaturas bastante mais baixas, desde que haja cuidado com a fricção.

A resistência ao calor dos polímeros, resulta da sua própria estrutura química. Com os polímeros, o ponto de fusão ou amolecimento situa-se num intervalo definido de temperaturas e não numa temperatura determinada como acontece com os monómeros. Isso deve-se ao facto de polimeros totalmente cristalinos não existirem. A temperatura de fusão pode-se considerar como uma medida da sua estrutura cristalina. Isto é, à temperatura de fusão as forças que mantêm em posição as moléculas encontram-se em equilíbrio com o movimento térmico, o que significa que quanto mais elevado for esse ponto, maior será a coesão intermolecular. Outro facto importante a assinalar é que o ponto de amolecimento de polimeros com moléculas lineares suficientemente compridas é praticamente independente do seu peso molecular, uma vez que a molécula, em regra, passa por várias zonas mais amorfas e é aí que a separação molecular por efeitos do calor se inicia. Por esse motivo se poderá dizer que o arrumo das micromoléculas, quanto mais perfeito fôr, mais elevado tornará o ponto de amolecimento. No exemplo já apontado, das novas fibras altamente cristalinas de polietileno, o seu ponto de fusão aumentou de 100-110 para 
$150^{\circ}$ apenas por um aumento de cristalinidade. A introdução de núcleos aromáticos ocasiona um aumento acentuado do ponto de amolecimento, uma vez que os anéis benzénicos aumentam a rigidez da cadeia molecular. Praticamente todas as fibras modernas caracterizadas por alta resistência ao calor são produzidas a partir de polímeros contendo vários anéis benzénicos na sua cadeia. Como exemplos mais flagrantes apontam-se a fibra PBI (American Celanese), obtida a partir do polybenzimidazole, capaz de resistir por curtos períodos a temperaturas de $500-800^{\circ}$. Outras ainda como Nomex, Aramid, Twaron, apresentam-se igualmente com capacidade de resistir a temperaturas de 300$-400^{\circ} \mathrm{C}$ por períodos mais ou menos longos.

A presença de átomos de halogénios, nomeadamente o fluor, igualmente provoca uma alta resistência ao calor nos polimeros.

Quanto às restantes características exigidas aos polímeros têxteis, elas são suficientemente evidentes para tornar desnecessária uma explicação adicional. Esclareça-se contudo, que a sua importância depende muito da aplicação final. Assim por exemplo, o facto das fibras Aramid terem uma cor dourada não impede a sua utilização em vestuários protectores.

\section{Preparação dos polímeros lineares}

Excluindo o caso dos polimeros lineares naturais (caso da celulose por exemplo), todos os restantes polimeros lineares são produzidos a partir de compostos de baixo peso molecular (monómeros) que se fazem reagir de modo a constituir longas cadeias.

Basicamente a polimerização pode-se fazer por a) adição b) condensação c) copolimerização. Na polimerização por adição, o polímero final obtem-se pela combinação dum certo número de monómeros, sem eliminação de qualquer substância. Para que isso seja possível, os monómeros contêm sempre pelo menos uma ligação dupla. O exemplo mais conhecido de polimerização por adição é certamente o do etileno para produzir o polietileno:

$$
\mathrm{n}\left(\mathrm{CH}_{2}=\mathrm{CH}_{2}\right) \rightarrow-\left(\mathrm{CH}_{2}-\mathrm{CH}_{2}\right)_{-}
$$

Na polimerização por condensação, a policondensação produz-se pela interacção dum ou mais compostos, com eliminação duma substância simples como por exemplo a água. É por este processo que se fabricam as poliamidas e os poliesteres. Assim por exemplo o polietileno de tereftalato, a matéria-prima para o fabrico das fibras poliester (Terylene, Dacron, Trevira, Tergal, etc.) é obtida pela combinação do ácido tereftálico com o etilenoglicol):<smiles>CCC(C)(O)C(=O)c1ccc(C(=O)c2ccc(C(=O)O)cc2)cc1</smiles>

Inicialmente, em vez do ácido tereftálico empregou-se o dimetiltereftalato, uma vez que o ácido tereftálico era bastante difícil de conseguir com a pureza necessária, ao contrário do outro produto que é destilável. Mais recentemente, novos processos de fabrico permitiram obter o ácido tereftálico suficientemente puro passando então a ser preferido pela indústria por ser mais rentável. Na prática, o fabrico do polietileno de tereftalato é efectuado em duas fases, pois só assim se consegue alcançar o alto grau de polimerização necessário. Na primeira fase, a mistura de ácido tereftálico e etilenoglicol é aquecida a cerca de $240 / 250^{\circ}$ em recipiente fechado. É a fase da esterificação que produz o monómero, com eliminação de água que é destilada:

$$
\begin{gathered}
\mathrm{HOOC}-\mathrm{COOH}+{ }_{2} \mathrm{HO}\left(\mathrm{CH}_{2}\right)_{2} \mathrm{OH} \\
\mathrm{HO}\left(\mathrm{CH}_{2}\right)_{2} \mathrm{OOC}-\mathrm{COO}\left(\mathrm{CH}_{2}\right)_{2} \mathrm{OH}+\mathrm{OH}_{2}
\end{gathered}
$$

A segunda fase, a policondensação, é efectuada sob um vácuo intenso, na presença de sais metálicos catalizadores (Sb, Ge, Co etc.), a cerca de $290 / 300^{\circ} \mathrm{C}$. Esta reacção é favorecida pela eliminação de etilenoglicol que é destilado e mais tarde purificado para futura utilização:

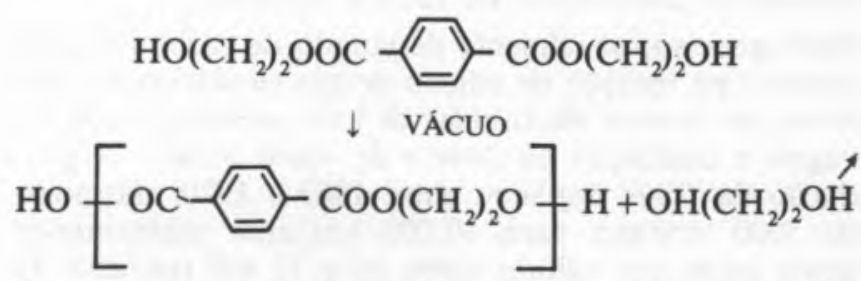

O grau exacto de polimerização requerido, é medido mediante análise laboratorial ou mais simplesmente pela determinação da viscosidade da massa fundida a partir do esforço exercido pelo motor acoplado ao agitador mecânico.

Finalmente, a copolimerização consiste em partir simultaneamente de dois ou mais monómeros que acabariam por polimerizar em conjunto, incorporados nas mesmas moléculas, alternadamente ou em blocos. Algumas fibras acrílicas são produzidas por copolimerização. A copolimerização é igualmente empregada por exemplo nos poliesteres para modificar algumas das suas propriedades, como seja facilitar o tingimento.

(1) J. Polymer Science 3, 609 (1948).

(2) R. Hill-Chem, and Ind. 36, 1083 (1954).

(3) High Performance Textiles 6.4 Outubro 1985

(4) Polyesters - V. Korshak e S. Vinogradova - pg. 308. 